Published by Al-Nahrain College of Medicine P-ISSN 1681-6579

E-ISSN 2224-4719

Email: iraqijms@colmed-alnahrain.edu.iq

http://www.colmed-alnahrain.edu.iq

http://www.iraqijms.net

\title{
Clinical Characteristics and Outcomes of Acute Coronary Syndromes in a Group of Iraqi Patients
}

\author{
Moayed B. Hamid FICMS \\ Dept. of Medicine, College of Medicine, Al-Nahrain University, Baghdad, Iraq
}

\begin{abstract}
Background
\end{abstract}

Objective

Methods

Results

Conclusion

Keywords

Coronary artery disease (CAD) is one of the most common diseases in the world. Acute coronary syndromes (ACS) represent the acute life-threatening phase of CAD. Epidemiology and management of ACS patients differ a lot between countries and there is a wide gap between guidelines and clinical practice.

To assess contemporary data on clinical characteristics and outcomes of patients with ACS in the Medical City Complex and to evaluate adherence to the guidelines' recommended treatment.

This is a descriptive study registry, started on January 2014 to June 2014, and involved 348 patients with ACS in the Medical City Complex.

The mean age of this study's population was $(60.3 \pm 11.2$ years), ranging between 29 to 90 years old. Most of patients were males (61\%). Only $233(67 \%)$ patients have typical angina. Symptom onsetto-admission time was delayed ( $\geq 12$ hours) in $65 \%$ of patients. The final diagnosis was: ST elevation myocardial infarction (STEMI) in 126 (36.2\%), non ST elevation myocardial infarction (NSTEMI) in 40 $(11.4 \%)$, and unstable angina (UA) in 182 (52.3\%) of patients. Electrocardiography was normal in $29 \%$ of patients with UA and $10 \%$ of patients with NSTEMI. Anterior territory was the most common location of ischemia (77\%). Hypertension $(47.9 \%)$ was the most significant risk factor followed by diabetes mellitus (41.6\%) and smoking (31.8\%). Reperfusion therapy for patients with STEMI was applied in 73(57\%) patients: $56(44.4 \%)$ by thrombolytic therapy, $24(19 \%)$ by percutaneous coronary intervention $(\mathrm{PCI})$ and $3(2.3 \%)$ by emergency CABG. Overall in-hospital mortality was $7.7 \%$ (15\%, $7.5 \%$ and $2.7 \%$ for STEMI, NSTEMI, and UA respectively).

There is lack of awareness of ischemic symptoms among our patients. There is high incidence of risk factors that can be modified by primary and secondary measures. There is underutilization of invasive management. We have a high mortality rates in patients with ACS.

DOI: $10.22578 / \mathrm{IJMS}$.14.4.3

List of abbreviation: $C A D=$ Coronary artery disease, $A C S=$ Acute coronary syndromes, STEMI = ST-elevation myocardial infarction, NSTEMI = Non-ST-elevation myocardial infarction, UA = unstable angina, ECG = Electrocardiography, NSTE-ACS = Non-ST-elevation acute coronary syndromes, $\mathrm{CCU}=$ cardiac care unit, $\mathrm{BTH}=$ Baghdad Teaching Hospital, ICHD = Iraqi Center for Heart Diseases, $\mathrm{PCI}=$ Percutaneous coronary intervention, $\mathrm{CAG}=$ Coronary angiography, $\mathrm{CABG}=$ Coronary artery bypass grafting

\section{Introduction}

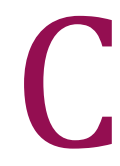
oronary artery disease (CAD) begins indolently as a fatty streak in the lining of the artery that soon progresses to narrow the coronary arteries and impair myocardial perfusion. It may present as chronic stable angina or acute coronary syndromes (ACS) in which, the atherosclerotic plaque ruptures and causes sudden thrombotic occlusion and acute ST-elevation myocardial infarction (STEMI), non-ST-elevation $\mathrm{MI}$ (NSTEMI) or unstable angina (UA). In STEMI, the occlusion is total, myocardial necrosis ensue with elevation of cardiac biomarkers and ST segment in the surface electrocardiography 
(ECG). In the other two syndromes, the occlusion is partial or involves a minor vessel, transient or permanent ST depression and or $\mathrm{T}$ inversion may occur with or without elevation of cardiac biomarkers in NSTEMI or UA respectively. Because NSTEMI and UA are indistinguishable at initial evaluation, and the entity of UA is receding as the sensitivity of biomarkers of myocardial injury increases, they are often described together as NSTE- ACS ${ }^{(1)}$.

Worldwide, the number of CAD deaths increased by 31\% between 1990 and 2010. In 2010 , CAD accounted for $13.3 \%$ of all deaths worldwide (2). Hospitals morbidity data provided by Iraqi Ministry of Health in 2004 demonstrates a $65 \%$ increase of the hospital admission due to CAD and stroke and more than a fivefold increase in outpatient visits with the same diagnoses between 1989 and $1999^{(3)}$. Iraq is in the top 25 countries in Middle East with age-adjusted CAD mortality rates of about 214 per $100,000^{(4)}$. It has been projected that between 1990 and 2020, CAD mortality in the Middle East countries will increase by $146 \%$ for women and $174 \%$ for men ${ }^{(5)}$.

Much of what we understand about risk and likelihood of cardiovascular disease, its incidence and prevalence are derived from 'western' data. However, there is now an increasing awareness of ethnic variations and risk, socio-cultural and socio-economic influences as well as geographical variations. In our country, because we are fighting the consequences of CAD rather than attacking its cause we may never success. We need to adopt a pro-active strategy based upon information and evidence. We initiated a limited ACS registry hoping that it would be a nidus for a national registry.

The aim of the study was to assess contemporary data on clinical presentation, risk factors, management and outcomes of patients with ACS in the Medical City Complex, and to evaluate adherence to the guidelines' recommended treatment.

\section{Methods}

The reported study was a descriptive study. It included 348 consecutive patients having ACS admitted to the cardiac care unit (CCU) of Baghdad Teaching Hospital (BTH) and Iraqi Center for Heart Diseases (ICHD) over 6 months from January 2014 to June 2014. BTH is a general hospital with daytime $\mathrm{PCl}$ facilities but no primary $\mathrm{PCl}$ program (PPCI). ICHD is tertiary center with $\mathrm{PPCl}$ facilities. Patients were subjected to full history and clinical examination, ECG, and echocardiography. Presenting symptoms were recorded as typical angina, atypical angina, dyspnea, cardiogenic shock, palpitation and/or cardiac arrest. Cardiac biomarkers were tested by "DIAQUICK" Cardiac Combo Cassette, which is a rapid visual immunoassay for the qualitative detection of human myoglobin, CK-MB, and cardiac troponin I; the test is positive if $c T n ~ I$ is $\geq 1$ $\mathrm{ng} / \mathrm{mL}, \mathrm{CK}-\mathrm{MB}$ is $\geq 5 \mathrm{ng} / \mathrm{mL}$, and myoglobin is $\geq$ $50 \mathrm{ng} / \mathrm{mL}$. Quantitative cardiac biomarkers assay was not available. Lipid profile tests were available for 27 patients only and were incomplete and therefore excluded from the study. The initial diagnosis was made by the attending-physician and patients were then classified as having STEMI, NSTEMI, or UA. The diagnosis of different type of ACS and definitions of data variables were based on American College of Cardiology (ACC) clinical data standard ${ }^{(6)}$. Patients were followed for complications and death during hospital stay.

\section{Statistical Analysis}

Continuous variables were presented as mean \pm standard deviation. Categorical variables were described as frequency and percentages. Continuous variables were assessed by t- test and Categorical variables by Chi-square test. The level of statistical significance was set at $P$ value $\leq 0.05$.

\section{Results}

\section{Initial diagnosis}

The study included 348 patients, 219 (63\%) admitted to the CCU of BTH and 129 (37\%) 
admitted to the CCU of ICHD. Of the 348 patients, 126 had STEMI (36.2\%), 40 had NSTEMI (11.4\%) and 182 had UA (52.3\%).

Baseline demographic and clinical characteristics are presented in Table (1) and (2) according to diagnosis and age groups respectively. Mean age of patients was $60.3 \pm 11.2$ year. The youngest patient in the study was 29 yrs old and the oldest was 90 yrs old. Men constituted $61 \%$ of patients. Hypertension (47.9\%) was the most significant risk factor followed by diabetes mellitus (41.6\%) and smoking (31.8\%).

Patients with NSTE-ACS were older than STEMI patients, although statistically not significant. UA and NSTEMI patients were of similar age.
Patients with STEMI had lower prevalence of the traditional cardiovascular risk factors: diabetes and hypertension compared with NSTE-ACS patients.

The patients were divided into three categories by age: $<45$ years, $45-54$ years and $\geq 55$ years. Men predominate all age group especially the young. Risk factors differed significantly among the three age groups (table 2). In patients $<45$ years old, $57 \%$ were smokers and this percentage decreased with increasing age $(p=$ 0.001). Younger patients were more likely to have a family history of CAD $(p=0.001)$ and were less likely to have diabetes ( $P$ value NS) or hypertension $(P=0.022)$.

Table 1. Distribution of clinical characteristics according to diagnosis

\begin{tabular}{cccccc}
\hline Risk factor & $\begin{array}{c}\text { STEMI } \\
\mathbf{n}=\mathbf{1 2 6}\end{array}$ & $\begin{array}{c}\text { NSTEMI } \\
\mathbf{n = 4 0}\end{array}$ & $\begin{array}{c}\text { UA } \\
\mathbf{n}=\mathbf{1 8 2}\end{array}$ & $\begin{array}{c}\text { Total } \\
\mathbf{n}=\mathbf{3 4 8}\end{array}$ & P value \\
\hline Median age & $58.9 \pm 11.6$ & $60 \pm 12.8$ & $61.2 \pm 10.5$ & $60.3 \pm 11.2$ & 0.863 \\
Male & $81(64.2 \%)$ & $26(65 \%)$ & $108(59.3 \%)$ & $215(61 \%)$ & 0.616 \\
DM & $39(30 \%)$ & $19(47 \%)$ & $87(47.8 \%)$ & $145(41.6 \%)$ & 0.009 \\
HTN & $45(35.7 \%)$ & $25(62.5 \%)$ & $106(58.2 \%)$ & $176(47.9 \%)$ & 0.001 \\
Smoking & $33(26.2 \%)$ & $16(40 \%)$ & $66(36.2 \%)$ & $111(31.8 \%)$ & 0.11 \\
h/o CAD & $17(13.4 \%)$ & $9(22.5 \%)$ & $78(42.8 \%)$ & $104(29.8 \%)$ & 0.001 \\
Family history & $3(2.3 \%)$ & $2(5 \%)$ & $3(2.3 \%)$ & $8(2.2 \%)$ & 0.761 \\
h/o PCI & $2(1.5 \%)$ & $5(12.5 \%)$ & $14(7.6 \%)$ & $22(6.3 \%)$ & 0.016 \\
h/o CABG & 0 & 0 & $4(2.1 \%)$ & $4(1.1 \%)$ & 0.452 \\
\hline
\end{tabular}

DM: diabetes mellitus, HTN: hypertension, h/o: history of, CAD: coronary artery disease, PCl: percutaneous coronary intervention, CABG: coronary artery bypass grafting

ECG was normal in $29 \%$ of patients with UA and $10 \%$ of NSTEMI. Anterior location of ischemia was the commonest (77\%) (Table 3).

Time to presentation: Accurate timing cannot be assured, however, $15 \%$ of patients with STEMI presented within $<6$ hours, $20 \%$ within $6-12$ hours, and $65 \% \geq 12$ hours. Median time was $11.5 \mathrm{hr}(1-24 \mathrm{hr})$. Sixty per cent of patients were admitted after 2:00 PM.

Reperfusion therapy for STEMI was applied in 73(57\%) patients: $56(44.4 \%)$ by thrombolytic therapy and $24(19 \%)$ by $\mathrm{PCl}$ (10 patients by primary $\mathrm{PCl}$ and 14 patients by rescue $\mathrm{PCl}$ ) and three (2.3\%) by emergency coronary artery bypass grafting (CABG). No patient was referred for primary or rescue $\mathrm{PCl}$ in $\mathrm{BTH}$.

Invasive management: CAG was done in $58 \%$ of all patients. It was negative in 6 patients labeled as UA. $\mathrm{PCl}$ was done in 108 (31\%) patients. See tables 5. IABP was used in three STEMI patients who were suffering from mechanical complications before referral for CABG.

In hospital mortality: $7.7 \%$ died in hospital (27 patients) due to cardiac arrest or cardiogenic shock (Table 5). 
Table 2. Distribution of clinical characteristics according to age groups

\begin{tabular}{cccccc}
\hline Risk factor & $\begin{array}{c}\mathbf{4 5} \mathbf{~ y r} \\
\mathbf{n = 2 1} \\
\mathbf{( 6 \% )}\end{array}$ & $\begin{array}{c}\mathbf{4 5 - 5 5} \mathbf{~ y r} \\
\mathbf{n = 1 0 5} \\
\mathbf{( 3 0 \% )}\end{array}$ & $\begin{array}{c}\mathbf{> 5 5} \mathbf{~ y r} \\
\mathbf{n = 2 2 2} \\
\mathbf{( 6 3 \% )}\end{array}$ & $\begin{array}{c}\text { Total } \\
\mathbf{n}=\mathbf{3 4 8}\end{array}$ & P value \\
\hline Male & $17(80.9 \%)$ & $\mathbf{7 7}(\mathbf{7 3 \% )}$ & $121(54 \%)$ & $215(61 \%)$ & 0.001 \\
DM & $7(30 \%)$ & $38(36.1 \%)$ & $107(48.1 \%)$ & $145(41.6 \%)$ & 0.059 \\
HTN & $5(23.8 \%)$ & $45(42.8 \%)$ & $126(56.7 \%)$ & $176(47.9 \%)$ & 0.022 \\
Smoking & $12(57.14 \%)$ & $48(45.7 \%)$ & $51(22.9 \%)$ & $111(31.8 \%)$ & 0.001 \\
h/o CAD & $3(14.2 \%)$ & $22(20.9 \%)$ & $79(35.5 \%)$ & $104(29.8 \%)$ & 0.007 \\
Family history & $3(14.3 \%)$ & $5(4.7 \%)$ & 0 & $8(2.2 \%)$ & 0.001 \\
h/o PCI & 0 & $7(6.6 \%)$ & $15(6.7 \%)$ & $22(6.3 \%)$ & 0.486 \\
h/o CABG & 0 & 0 & $4(1.8 \%)$ & $4(1.1 \%)$ & 0.317 \\
\hline
\end{tabular}

DM: diabetes mellitus, HTN: hypertension, h/o: history of, CAD: coronary artery disease, PCl: percutaneous coronary intervention, CABG: coronary artery bypass grafting

Table 3. ECG changes

\begin{tabular}{|c|c|c|c|}
\hline ST elevation & \multicolumn{3}{|c|}{$126(36.2 \%)$} \\
\hline ST depression & \multicolumn{3}{|c|}{$158(71 \%)$ of all NSTE- ACS } \\
\hline LBBB & \multicolumn{3}{|c|}{$7(2 \%)$ one diagnosed as STEMI, the rest as UA } \\
\hline Normal & \multicolumn{3}{|c|}{$53(29 \%)$ of UA and $4(10 \%)$ of NSTEMI } \\
\hline location & Anterior $77 \%$ & Lateral $3.2 \%$ & Posterior $2.3 \%$ \\
\hline
\end{tabular}

Table 4. Invasive management

\begin{tabular}{ccccc}
\hline Procedure & STEMI & NSTEMI & UA & Total \\
& $\mathbf{N}=\mathbf{1 2 6}$ & $\mathbf{n = 4 0}$ & $\mathbf{n}=\mathbf{1 8 2}$ & $\mathbf{n = 3 4 8}$ \\
\hline CAG & $32(25 \%)$ & $14(35 \%)$ & $124(68 \%)$ & $202(58 \%)$ \\
PCI & $24(19 \%)$ & $6(15 \%)$ & $78(42 \%)$ & $108(31 \%)$ \\
CABG & $4(3 \%)$ & $8(2 \%)$ & $40(21.9 \%)$ & $52(14 \%)$ \\
\hline
\end{tabular}

STEMI: ST elevation myocardial infarction, NSTEMI: non-ST elevation myocardial infarction, UA: unstable angina, CAG: coronary angiography, $\mathrm{PCl}$ : percutaneous coronary intervention, $\mathrm{CABG}$ : coronary artery bypass grafting

Table 5. In-hospital outcomes in medical city complex

\begin{tabular}{cccccc}
\hline Complications & $\begin{array}{c}\text { STEMI } \\
\mathbf{n = 1 2 6}\end{array}$ & $\begin{array}{c}\text { NSTEMI } \\
\mathbf{n = 4 0}\end{array}$ & $\begin{array}{c}\text { UA } \\
\mathbf{n = 1 8 2}\end{array}$ & $\begin{array}{c}\text { Total } \\
\mathbf{n = 3 4 8}\end{array}$ & P value \\
\hline Arrhythmias & 14 & 3 & 6 & $23(6.6 \%)$ & 0.024 \\
Heart Failure & 10 & 2 & 13 & $25(7.2 \%)$ & 0.821 \\
Cardiogenic shock & 11 & 0 & 3 & $14(4 \%)$ & 0.02 \\
Mechanical & 3 & 0 & 0 & $3(0.8 \%)$ & 0.264 \\
Stroke & 0 & 2 & 0 & $2(0.5 \%)$ & 0.036 \\
\hline Death & $19(15 \%)$ & $3(7.5 \%)$ & $5(2.7 \%)$ & $27(7.7 \%)$ & 0.001 \\
\hline
\end{tabular}




\section{Discussion}

Results are compared with that of GRACE study (the largest global registry that involved 6073 cases from 234 hospitals in 13 countries from
Europe, North and South America, Australia, and New Zealand ${ }^{(7)}$, as well as various registries (table 6).

Table 6. Comparison distribution of risk factors with other studies

\begin{tabular}{|c|c|c|c|c|c|c|c|c|}
\hline Item & $\begin{array}{l}\text { Current } \\
\text { Study }\end{array}$ & $\begin{array}{c}\text { GRACE } \\
\text { (7) }\end{array}$ & $\begin{array}{c}\text { EHS-ACS II } \\
\text { (8) }\end{array}$ & $\begin{array}{c}\text { Cairo } \\
\text { (9) }\end{array}$ & $\begin{array}{l}\text { UAE } \\
\text { (10) }\end{array}$ & $\begin{array}{c}\text { Czech } \\
\text { (11) }\end{array}$ & $\begin{array}{c}\text { Brazil } \\
\text { (12) }\end{array}$ & $\begin{array}{c}\text { Polish } \\
\text { (13) }\end{array}$ \\
\hline $\begin{array}{l}\text { Pt } \\
\text { no. }\end{array}$ & 348 & 60723 & 6385 & 401 & 1840 & 1221 & 860 & 10093 \\
\hline Age & 61 & $66.3^{* *}$ & $64.7^{* *}$ & $54.4^{* *}$ & $51^{* *}$ & $68^{* *}$ & $62.6^{*}$ & $65.6^{* *}$ \\
\hline Male & 63.2 & $67^{\mathrm{NS}}$ & $70.1^{* *}$ & $79^{* *}$ & $93.1^{* *}$ & $63.4^{\mathrm{NS}}$ & $58.3^{\mathrm{NS}}$ & $61.4^{\mathrm{NS}}$ \\
\hline $\begin{array}{l}\text { HTN } \\
(\%)\end{array}$ & 49.7 & $60^{* *}$ & $57.3^{* *}$ & $55.36^{*}$ & $34.6^{* *}$ & $70.2^{* *}$ & $78.1^{* *}$ & $68.7^{* *}$ \\
\hline $\begin{array}{l}\text { DM } \\
(\%)\end{array}$ & 41.1 & $25^{* *}$ & $24^{* *}$ & $37.66^{*}$ & $38.9^{\mathrm{NS}}$ & $35.6^{*}$ & $31.6^{* *}$ & $24.1^{* *}$ \\
\hline $\begin{array}{c}\text { Smoking } \\
(\%)\end{array}$ & 31 & $58^{* *}$ & $36.8^{*}$ & $61^{* *}$ & $46.4^{* *}$ & $30.9^{\text {NS }}$ & $26^{*}$ & $28.4^{\mathrm{NS}}$ \\
\hline $\begin{array}{l}\text { CAD } \\
(\%)\end{array}$ & 29.9 & $59^{* *}$ & $22.5^{\mathrm{NS}}$ & $41.8^{* *}$ & $23.7^{* *}$ & $25^{*}$ & $47.6^{* *}$ & $24.7^{*}$ \\
\hline $\begin{array}{c}\text { Death } \\
(\%)\end{array}$ & 7.7 & $5^{*}$ & $4^{*}$ & $4.2^{*}$ & $3.3^{* *}$ & $5.7^{\mathrm{NS}}$ & $4.8^{*}$ & $5.6^{\mathrm{NS}}$ \\
\hline
\end{tabular}

NS $=$ no significant difference $(p>0.05),{ }^{*}=$ Significant difference $(p \leq 0.05), * *$ Highly significant difference $(p \leq$ $0.001)$.

Pt no.: patients number, HTN: hypertension, DM: diabetes mellitus, CAD: coronary artery disease, GRACE: global registry of acute coronary events, EHS-ACS: Euro Heart Study of acute coronary syndromes, UAE: United Arab Emirates

In this study, the median time from onset of symptoms to CCU arrival (11.9 hr) was the much later than in UAE registry (127 minutes), GRACE (140 minutes) ${ }^{(7)}$, Cairo (165 minutes) ${ }^{(9)}$ and even Russia (4.33 hrs for STEMI and 7.42 hrs for NSTE-ACS) ${ }^{(14)}$ or India $(6 \mathrm{hrs})^{(15)}$. This indicates lack of awareness of alarming symptoms of ischemia and shows the need for more public health education.

The mean age of our patients is significantly lower than that in European studies and higher than the Gulf and Egypt studies and so cannot be explained on economic base only; genetic and cultural factors need to be studied.
Hypertension is the most prevalent risk factor in this study. According to a population-based survey conducted in 1979 by Alwan, hypertension comprises $12 \%$ of the Iraqi population $^{(3)}$. This increased to $40.4 \%$ on 2006 according to a large national survey by the Ministry of Health; the prevalence of selfreported hypertension was $19 \%$ indicating low awareness and $8.7 \%$ of patients were taking herbal or traditional remedy ${ }^{(16)}$. On 2012, a small report from selected primary health care centers in Nasiriya city reported a similar prevalence $(46.1 \%)^{(17)}$. In a local study of 110 patients with hypertension and myocardial infarction the salt-free diet and drug 
noncompliance rate was seen in $69 \%$ and $71 \%$ of patients respectively ${ }^{(18)}$. All these studies indicate increasing prevalence of hypertension over time among Iraqi population but with poor patient awareness and compliance and thus less control and more complications. However, hypertension was less prevalent compared to other international studies. Whether this is related to sample volume and methodology or ethnicity, which is known to plays a major role in the prevalence of hypertension, its response to treatment and related mortality; needs to be clarified by further study ${ }^{(19-22)}$.

Diabetes has the highest incidence in our patients compared to other studies. According to Ministry of Health survey on 2006 diabetes affects $10.4 \%$ of Iraqi population with $15.6 \%$ of them were taking herbal or traditional remedy for treatment (16). A local study in Basrah involved 5,445 persons on 2014 showed that $19.7 \%$ had diabetes with $70.3 \%$ had a body mass index $\geq 25 \mathrm{~kg} / \mathrm{m}^{2}{ }^{(23)}$. In another local study in Basrah included 1079 patients the mean glycated hemoglobin (HbA1c) was $9.46 \%$ $\pm 2.0 \%$ and only $5.5 \%$ achieved the target of $\mathrm{HbA1C}$ of $<7 \%{ }^{(24)}$. These studies confirm that we are still lagging in diabetic control from guidelines.

Smoking is less prevalent in our study compared with international studies ${ }^{(7-13)}$. As supported by some of the aforementioned local studies, smoking ranges between 16.9 to $25 \%$, is a finding that depends on the history given by the patient.

The final diagnoses (STEMI 36.2\%, and NSTEACS $63.7 \%$ in the form of NSTEMI $11.4 \%$ and UA 52.3\% are comparable to that in the largest global registry GRACE ${ }^{(7)}$ (STEMI 34\% and NSTEACS $59 \%$ in the form of NSTEMI $30 \%$ and UA $29 \%$ ), but the proportion of UA is higher than NSTEMI within our NSTE-ACS category. The use of insensitive rapid visual immunoassay for detection of cardiac biomarkers, and rare use of serial testing for biomarkers may be responsible for this overlap between NSTEMI and UA. In addition, it is possible that some of the patients were overdiagnosed because the criteria for UA are rather liberal and do not require ECG changes. Typical ischemic ECG abnormalities were absent in about $29 \%$ of UA and $10 \%$ of NSTEMI patients.

In GRACE study, CAG was performed in $62 \%$ of STEMI (followed by $\mathrm{PCl}$ in $45 \%$ and by CABG in $4 \%$ ), $57 \%$ of NSTEMI (followed by $\mathrm{PCl}$ in $32 \%$ and by CABG in $7 \%$ ), and in $49 \%$ of UA patients (followed by $\mathrm{PCl}$ in $23 \%$ and by CABG in $6 \%$ ) ${ }^{(7)}$. In Euro Heart Study-ACS I on 2001 and ACS II on 2004 there is significant shift from fibrinolytic therapy to primary $\mathrm{PCl}(\mathrm{PPCl})$. The use of $\mathrm{PPCl}$ rose from 37 to $59 \%{ }^{(8)}$. In the Czech Republic, only $21 \%$ of the patients with STEMI presented to a regional hospital; the majority were referred directly to a cardiocenter by emergency medical personnel $\left.{ }^{(11}\right)$. In comparison, we have underutilization of $\mathrm{PCl}$ in ACSs in general and especially in STEMI due to limited availability of $24 \mathrm{hrs}$ PCI facilities with expert staff and poor referral from general hospitals. In some high-income countries like in Gulf registry (Gulf RACE) ${ }^{(25)}$ primary $\mathrm{PCl}$ was performed in $7 \%$ of cases and in a large US registry primary $\mathrm{PCl}$ was performed in $22 \%$ of STEMI patients (26), suggesting the effect of administrative other than financial factors.

Mortality in current study is higher than in most other studies except for Russia ${ }^{(14)}$ and India ${ }^{(15)}$, which showed a similar high mortality rates (9.7\% and $6.5 \%$ respectively), similar long time to presentation and underutilization of invasive management ( $\mathrm{PCl}$ in $18.7 \%$ of STEMI and $11.4 \%$ of NSTE- ACS in Russia registry and $8 \%$ primary $\mathrm{PCl}$ in India registry). While the very low mortality in Taiwan (1.3\%) ${ }^{(27)}$ and UAE $(3.3 \%)^{(10)}$ registries are related to exclusion of patients with $>12 \mathrm{hrs}$ to presentation in the former and the high percentage of young foreign patients in the later.

\section{Limitations}

The participating two hospitals are teaching hospitals, one with primary $\mathrm{PCl}$ facility and one without. Thus, the present findings may not be 
generalized to patients of other hospital types. Lipid profile and body mass index were not checked. Only conventional coronary disease risk factors were identified. The study reports only in-hospital outcome, which may be inadequate to capture the true burden of CAD and the impact of our practice on the outcome on long term basis.

This study concluded that there is a long time delay from onset of symptoms to hospital admission among our patients indicating lack of awareness of ischemic symptoms and it seems to be the most detrimental factor. There is high incidence of risk factors that can be modified by primary and secondary measures. There is underutilization of invasive management. We have a high mortality rates in patients with ACS secondary to the aforementioned factors.

\section{Acknowledgments}

I would like to thank all the physicians, nurses and other staff in the Medical City Complex involved in the enrolment of patients in this study.

\section{Conflict of interest}

No potential conflicts of interest.

\section{Funding}

The author received no specific grant from any funding agency for preparing this article.

\section{References}

1. Giugliano RP, Cannon CP, Braunwald E. Non-ST elevation acute coronary syndromes. In: Mann DL, Zipes DP, Libby $P$, et al (eds). Braunwald's heart disease: a textbook of cardiovascular medicine. 10th ed. Philadelphia: Saunders; 2015. p. 1155

2. Gaziano TA, Prabhakaran D, Gaziano JM. Global burden of cardiovascular disease. In: Mann DL, Zipes $D P$, Libby $P$, et al (eds). Braunwald's heart disease: a textbook of cardiovascular medicine. 10th ed. Philadelphia: Saunders; 2015. p. 4-8.

3. Alwan A. Cardiovascular diseases in health in Iraq, Review of the current health situation, challenges facing reconstruction of the health sector, and our vision for the immediate future. Ministry of Health, 2004. P. 21-2.

4. World Health Rankings,

2011
5. Yusuf S, Reddy S, Ounpuu S, et al. Global burden of cardiovascular diseases, part I: general considerations, the epidemiological transition, risk factors and impact of urbanization. Circulation. 2001; 104: 2746-53.

6. Cannon CP. 2013 ACCF/AHA Key data elements and definitions for measuring the clinical management and outcomes of patients with acute coronary syndromes and coronary artery disease. J Am Coll Cardiol. 2013; 61(9): 992-1025.

7. The Global Registry of Acute Coronary Events (GRACE). Available at www.outcomesumassmed.org/grace

8. Mandelzweig L, Battler A, Boyko V, et al. The second Euro heart survey on acute coronary syndromes: Characteristics, treatment, and outcome of patients with ACS in Europe and the Mediterranean Basin in 2004. Eur Heart J. 2006; 27: 2285-93.

9. Shaheen S, Magdi A, Esmat I, et al. National Heart Institute Acute Coronary Syndrome Registry. Med J Cairo Univ. 2012: 80(2): 141-149.

10. Yusufali AM, AlMahmeed W, Tabatabai S. Acute coronary syndrome registry from four large centres in United Arab Emirates (UAE-ACS Registry). Heart Asia. 2010: 118e121. doi:10.1136/ha.2009.001495.

11. Tousek $P$, Tousek F, Horak D, et al. The incidence and outcomes of acute coronary syndromes in a central European country: Results of the $\mathrm{CZECH}-2$ registry. Int J Cardiol. 2014; 173: 204-8.

12. Dos Santos ES, Minuzzo L, Pereira MP, et al. Acute Coronary Syndrome Registry at a Cardiology Emergency Center. Arq Bras Cardiol. 2006; 87: 544-9.

13. Poloński L, Gąsior M, Gierlotka $M$, et al. Polish Registry of Acute Coronary Syndromes (PL-ACS) Characteristics, treatments and outcomes of patients with acute coronary syndromes in Poland. Kardiol Pol. 2007; 65: 861-72.

14. Erlikh AD, Gratsianskiĭ NA. Registry of acute coronary syndromes RECORD. Characteristics of patients and results of in-hospital treatment. Kardiologiia. 2009; 49(7-8): 4-12.

15. Denis X, Prem P, Devereaux PJ, et al. Treatment and outcomes of acute coronary syndromes in India (CREATE): a prospective analysis of registry data. Lancet. 2008; 371: 1435-42.

16. Ministry of Health, Directorate of Public Health and Primary Health Care and Ministry of Planning and Development Cooperation, in collaboration with World Health Organization. Chronic NonCommunicable Diseases Risk Factors Survey in Iraq, 2006. Available at www.fineprint.com.

17. Al-Lami F, Mousa A. Prevalence of undetected, untreated, and uncontrolled hypertension among attendants of primary health care centers in Nasiriya city, Iraq," in Proceedings of the 61st Annual Epidemic Intelligence Service Conference (EIS '12), , 
Centers for Disease Control and Prevention, Atlanta, Ga, USA, April 2012. p. 99

18. Hasan ZN, Hussein MQ, Haji GF. Hypertension as a risk factor: is it different in ischemic stroke and acute myocardial infarction comparative cross-sectional study. Int J Hypertens. 2011; 2011: 701029. doi: 10.4061/2011/701029.

19. Kramer $\mathrm{H}$, Han $\mathrm{C}$, Post W. racial/ethnic differences in hypertension and hypertension treatment and control in the multi-ethnic study of atherosclerosis (MESA). Am J Hypertens. 2004; 17: 963-70.

20. Bell AC, Linda S. Adair LS, Popkin BM. Ethnic differences in the association between body mass index and hypertension. Am J Epidemiol. 2002: 155(4): 346-53.

21. Lane DA, Lip GYH. Ethnic differences in hypertension and blood pressure control in the UK. Q J Med. 2001; 94: 391-4.

22. Wang Z, Chen S, Zhang L, et al. Association between variation in the genes DDAH1 and DDAH2 and hypertension among Uygur, Kazakh and Han ethnic groups in China. Sao Paulo Med J. 2016; 134(3): 20510.

23. Mansour AA, Al-Maliky AA, Kasem B, et al. Prevalence of diagnosed and undiagnosed diabetes mellitus in adults aged 19 years and older in Basrah, Iraq. Diabetes Metab Syndr Obes. 2014; 7: 139-44.
24. Mansour AA, Ajeel NAH. Atherosclerotic cardiovascular disease among patients with type 2 diabetes in Basrah. World J Diabetes. 2013: 4: 82-7.

25.Zubaid $M$, Rashed WA, Al-Khaja $N$, et al. Clinical presentation and outcomes of acute coronary syndromes in the gulf registry of acute coronary events (Gulf RACE). Saudi Med J. 2008; 29: 251-5.

26. Pitta SR, Grzybowski M, Welch RD, et al. ST-segment depression on the initial electrocardiogram in acute myocardial infarction - prognostic significance and its effect on short-term mortality: a report from the National Registry of Myocardial Infarction (NRMI-2, 3, 4). Am J Cardiol. 2005; 95: 843-8.

27. Shyu KG, Wu CJ, Mar GY, et al. Clinical characteristics, management and in-hospital outcomes of patients with acute coronary syndrome observations from the Taiwan ACS full spectrum registry. Acta Cardiol Sin. 2011; 27: 135-44.

E-mail: moayed.basheer@yahoo.com
Received 18 ${ }^{\text {th }}$ Jan. 2016: Accepted $3^{\text {rd }}$ Oct.
2016

